\title{
Correction to: Safety of orogastric tubes in foregut and bariatric surgery
}

\author{
Kulvir Nandra ${ }^{1}\left[\right.$ : Richard Ing ${ }^{1}$
}

Published online: 12 April 2019

(C) The Author(s) 2019

\section{Correction to: Surgical Endoscopy (2018) 32:4068-4070 https://doi.org/10.1007/s00464-018-6269-y}

The article "Safety of orogastric tubes in foregut and bariatric surgery," written by Kulvir Nandra and Richard Ing, was originally published Online First without Open Access. After publication in volume 32, issue 10, pages 4068-4070, the authors decided to opt for Open Choice and to make the article an Open Access publication. Therefore, the copyright of the article has been changed to $\odot$ The Author(s) 2018 and the article is forthwith distributed under the terms of the Creative Commons Attribution 4.0 International License http://creativecommons.org/licenses/by/4.0/(), which permits use, duplication, adaptation, distribution and reproduction in any medium or format, as long as you give appropriate credit to the original author(s) and the source, provide a link to the Creative Commons license, and indicate if changes were made.

The original article was updated to reflect this change.

The original article can be found online at https://doi.org/10.1007/ s00464-018-6269-y.

Kulvir Nandra

Kulvir.Nandra@jefferson.edu

1

\footnotetext{
Department of Surgery, Thomas Jefferson University

Hospital, 1015 Walnut Street, Curtis Building, Suite 620,

Philadelphia, PA 19107, USA
} 